\title{
Laju Pertumbuhan Dimensi Panjang Tubuh Kerbau Lumpur di Kabupaten Lombok Tengah
}

\section{(THE GROWTH RATE OF LENGTH DIMENSION OF SWAMP BUFFALO IN CENTRAL LOMBOK REGENCY)}

\author{
Ni Luh Lasmi Purwanti ${ }^{1 *}$, I Putu Sampurna ${ }^{2}$, Ni Nyoman Werdi Susari ${ }^{3}$ \\ ${ }^{1}$ Mahasiswa Sarjana Kedokteran Hewan, Fakultas Kedokteran Hewan, Universitas Udayana, \\ Jln. PB Sudirman Denpasar Bali; ${ }^{2}$ Laboratorium Biostatistika Veteriner, Fakultas \\ Kedokteran Hewan, Universitas Udayana, Jln. PB Sudirman Denpasar Bali; ${ }^{3}$ Laboratorium \\ Anatomi Veteriner, Fakultas Kedokteran Hewan, Universitas Udayana, Jln. PB Sudirman \\ Denpasar Bali. *Email: lasmipurwanti@gmail.com
}

\begin{abstract}
Abstrak
Penelitian ini bertujuan untuk mengetahui laju pertumbuhan dimensi panjang tubuh kerbau lumpur (Bubalus bubalis) jantan dan betina di Kabupaten Lombok Tengah. Penelitian ini mengukur 54 ekor kerbau lumpur (jantan 27 ekor dan betina 27 ekor) asal Lombok Tengah. Umur kerbau yang diukur mulai dari umur sembilan bulan sampai dengan 20 bulan, dan masing-masing kerbau lumpur jantan dan betina diukur pada umur yang sama terdiri dari tiga ekor. Pengukuran dimensi panjang tubuh dilakukan tiap bulan sebanyak 18 ekor terdiri dari sembilan ekor jantan dan sembilan ekor betina. Sehingga pengukuran dilakukan selama tiga bulan. Data yang diperoleh dianalisis dengan multivariant dan regresi power. Hasil analisis multivariant menunjukan bahwa laju pertumbuhan dimensi panjang tubuh kerbau lumpur jantan berbeda nyata dengan betina $(\mathrm{P}<0,05)$ di Kabupaten Lombok Tengah. Hasil analisis regresi power menunjukan koefisien korelasi masing-masing dimensi panjang kepala, tanduk, telinga, leher, tubuh dan ekor kerbau lumpur jantan dan betina berbeda nyata $(\mathrm{P}<0,05)$. Dimensi panjang tubuh kerbau lumpur jantan yang paling dini tumbuh yaitu dimensi panjang kepala kemudian disusul oleh panjang tubuh, panjang ekor, panjang leher, panjang telinga, dan yang terakhir tumbuh adalah panjang tanduk. Sedangkan dimensi panjang tubuh kerbau lumpur betina yang paling dini tumbuh yaitu dimensi panjang kepala, panjang tubuh dan panjang telinga, kemudian disusul oleh panjang ekor, panjang leher dan terakhir panjang tanduk yang memiliki laju pertumbuhan belakangan.
\end{abstract}

Kata kunci: Kerbau lumpur; laju pertumbuhan; dimensi panjang; jantan; betina

\begin{abstract}
This study aims to determine the growth rate of length dimension of male and female swamp buffalo (Bubalus bubalis) in Central Lombok. This study measured 54 swamp buffaloes (27 male and 27 female) from Central Lombok Regency. The age of buffalo is measured from the age of nine months to 20 months, and each 3 male and female swamp buffalo is measured at the same age. The measurement of body length dimensions carried out every month as many as 18 buffalo consisted of nine male and nine females. So that measurements are made for 3 months. The data obtained were analyzed by multivariant and power regression. The results of the multivariant analysis showed that the growth rate of male buffalo body dimensions was significantly different from the females $(\mathrm{P}<0.05)$ in Central Lombok Regency. The results of the power regression analysis showed that the correlation coefficients of each dimension of head, horn, ear, neck, body and male and female swamp buffalo were significantly different $(\mathrm{P}<0.05)$. The earliest dimensions of the male buffalo body growth are the dimensions of the head length then followed by body length, tail length, neck length, ear length, and the last is the length of the horn. While the longest dimensions of the female buffalo mud body grow are dimensions of head length, body length and ear length, then followed by tail length, neck length and finally horn length which has a later growth rate.
\end{abstract}

Keywords: Swamp buffalo; growth rate; length dimension; male; female 


\section{PENDAHULUAN}

Kabupaten Lombok Tengah berada di Provinsi Nusa Tenggara Barat dengan Ibu kota Praya dan luas wilayah 1.208,39 km². Kabupaten Lombok Tengah merupakan salah satu penghasil kerbau di Provinsi Nusa Tenggara Barat. Jumlah populasi ternak kerbau di Kabupaten Lombok Tengah pada tahun 2016 yaitu sebesar 19.770 ekor (Disnakkeswan Prov NTB, 2018). Seluruh kerbau yang ada di Provinsi NTB merupakan jenis kerbau lumpur (swamp buffalo) dan tidak ditemukan dari jenis kerbau sungai (river buffalo) (Erdiansyah dan Anggraeni, 2008).

Ternak kerbau potensial dikembangkan di Kabupaten Lombok Tengah, yang ditunjang oleh daya dukung lingkungan yaitu sumber daya lahan dan adaptasi kerbau (Sukri et al., 2016). Sistem pemeliharaan kerbau di Kabupaten Lombok Tengah menggunakan sistem pengembalaan di padang rumput maupun rawa-rawa dengan berbagai tanaman hijau disekitarnya. Kerbau memiliki kontribusi terhadap diversitas pangan yaitu sebagai penghasil daging dan susu serta dapat meningkatkan pendapatan masyarakat Kabupaten Lombok Tengah. Kontrubusi lainnya dalam sosial dan budaya, kerbau digunakan sebagai sarana upacara adat perkawinan yaitu untuk seserahan pengantin wanita dan hidangan makanan (Samsuandi et al. 2016).

Pertumbuhan diartikan sebagai pertambahan berat badan atau ukuran tubuh sesuai dengan umur hewan (Sugeng, 2006). Pertumbuhan tubuh secara keseluruhan dapat diukur melalui pengukuran dimensi tubuh yaitu tinggi pundak, panjang badan, lingkar dada (Rachma, 2007). Dengan mengetahui ukuran dimensi tubuh ternak maka, pertumbuhan kerbau dapat diperkirakan dan merupakan hal yang penting dalam suatu produksi ternak. Pencapaian produksi ternak kerbau yang tinggi, diperoleh ukuran pertumbuhan tubuh yang baik. Soeparno (2005) menyatakan setiap kenaikan berat tubuh selama pertumbuhan terdapat proporsi organ dan jaringan yang berbeda. Menurut Rachma et al. (2011) sistem manajemen pakan nutrisi merupakan faktor utama dalam pola pertumbuhan maupun perkembangan. Sehingga diperlukan pakan yang sesuai untuk memenuhi kebutuhan nutrisi ternak kerbau.

Dalam suatu penelitian Sukri et al. (2016) tentang karakter morfologi kerbau (Bubalus bubalis) di Kabupaten Lombok Tengah didapatkan hasil bahwa ada perbedaan panjang kepala, panjang leher pada masing-masing kelompok umur, sedangkan panjang ekor tidak ditemukan perbedaan. Penelitian Sukri et al. (2016) merupakan penelitian awal yang mengkaji karakter morfologi kerbau (Bubalus bubalis) di Kabupaten Lombok Tengah. Parameter penelitian Sukri et al. (2016) yaitu panjang kepala, leher, tubuh, kaki dan ekor. Parameter penelitian tersebut masih terbatas, maka penulis tertarik melakukan penelitian mengenai laju pertumbuhan dimensi panjang tubuh kerbau lumpur (Bubalus bubalis) di Kabupaten Lombok Tengah yang bertujuan untuk melengkapi parameter penelitian Sukri et al. (2016) serta memperkenalkan dan memberikan informasi mengenai laju pertumbuhan kerbau lumpur di Kabupaten Lombok Tengah.

\section{METODE PENELITIAN}

\section{Sampel Penelitian}

Sampel yang digunakan dalam penelitian ini terdiri dari 54 ekor kerbau lumpur (jantan 27 ekor dan betina 27 ekor) asal Lombok Tengah. Umur kerbau yang diukur mulai dari umur sembilan bulan sampai dengan 20 bulan, dan masingmasing kerbau lumpur jantan dan betina diukur pada umur yang sama terdiri dari tiga ekor. Alat yang digunakan dalam penelitian ini yaitu pita ukur (Panjangnya $150 \mathrm{~cm}$ ), tongkat ukur buku, alat tulis, dan kamera untuk dokumentasi. 


\section{Metode Pengukuran}

Pengukuran dimensi panjang tubuh kerbau lumpur jantan betina dilakukan tiap bulan sebanyak 18 ekor terdiri dari sembilan ekor jantan dan sembilan ekor betina. Sehingga pengukuran dilakukan selama tiga bulan. Pengukuran dilakukan dengan pita ukur dan tongkat ukur, dengan cara sebagai berikut (Sampurna, 2013), Panjang kepala diukur dari cermin hidung (planum nasolabiale) sampai perbatasan intercornuale dorsale garis median. Panjang tanduk di ukur dari pangkal tanduk dengan ujung tanduk (Os. cornualis).
Panjang telinga di ukur dari pangkal telinga dengan ujung telinga. Panjang leher diukur dari perbatasan intercornuale sampai pada garis tegak yang ditarik dari tuberositas lateralis dari humerus (sendi bahu atau articulatio scapulo humeri). Panjang tubuh diukur dari garis tegak tuberositas lateralis dari humerus (depan sendi bahu) sampai dengan leher tuber ischii. Panjang ekor diukur dari jarak antara pangkal ekor (vertebrae coccygea pertama) dengan ujung tulang ekor terakhir (vertebrae coccygea 20 ).

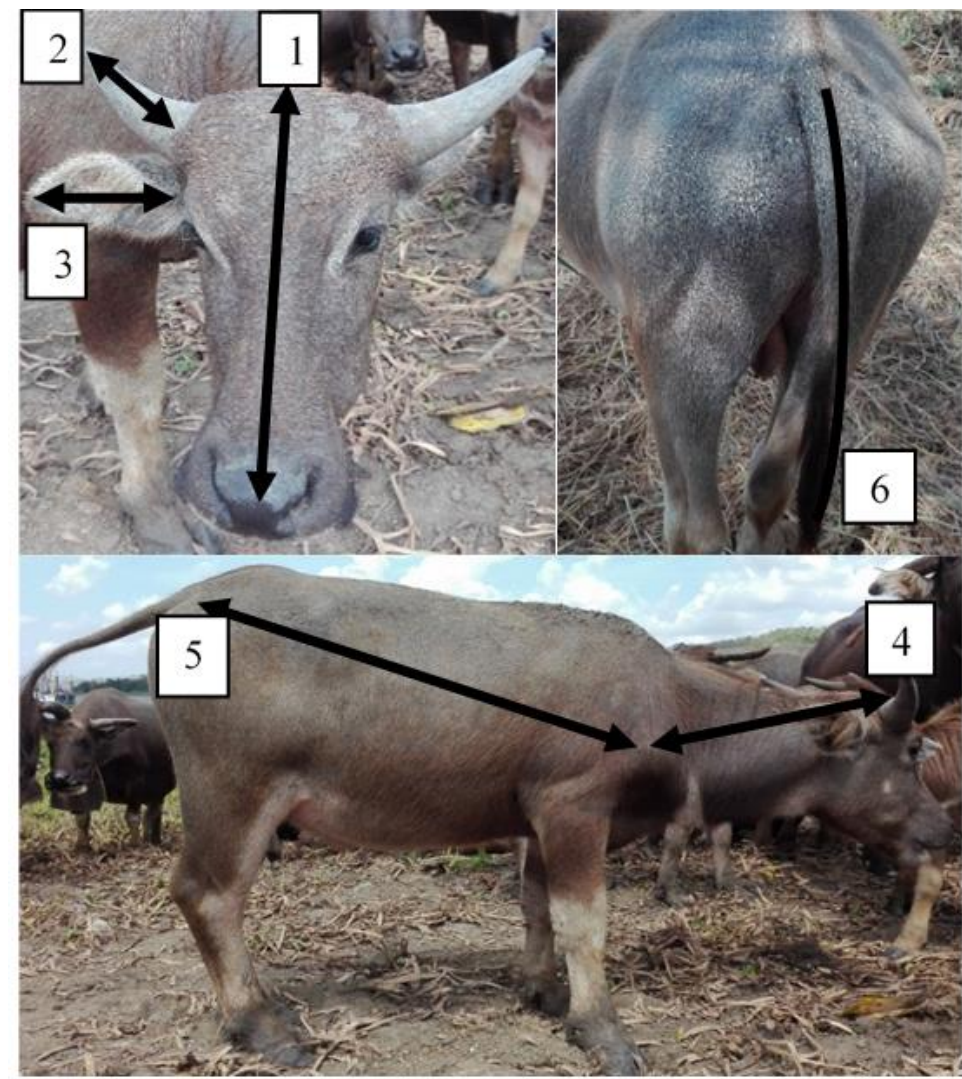

Gambar 1. Metode pengukuran dimensi panjang tubuh kerbau lumpur

\section{Analisis Data}

Data dianalisis dengan mengunakan Multivariate atau MANOVA. Jika interaksi antara jenis kelamin dengan umur berbeda nyata $(\mathrm{P}<0,05)$ maka persamaan antara jantan dan betina dipisahkan. Untuk mencari bagian panjang tubuh yang mengalami pertumbuhan dan perkembangan yang lebih cepat menggunakan analisis regresi power dengan persamaan : $\mathrm{Y}=\mathrm{ax}^{\mathrm{b}}$. Keterangan rumus $\mathrm{Y}$ adalah bagian-bagian dimensi panjang tubuh, a adalah konstanta, b adalah koefisien laju pertumbuhan, dan $\mathrm{x}$ adalah panjang keseluruhan tubuh.

\section{HASIL DAN PEMBAHASAN}

\section{Hasil}

Hasil MANOVA menunjukkan bahwa jenis kelamin berbeda nyata $(\mathrm{P}<0,01)$ 
terhadap ukuran dimensi panjang tubuh serta terdapat interaksi antara jenis kelamin dengan umur. Berdasarkan hasil tersebut, maka analisis regresi power antara kerbau lumpur jantan dan betina dipisahkan. Hasil analisis regresi power kerbau lumpur jantan pada Tabel 1 sedangkan kerbau lumpur

Tabel 1. Hasil analisis regresi power dimensi panjang tubuh kerbau lumpur jantan

\begin{tabular}{lccrrl}
\hline Dimensi Panjang & R & Konstanta & Laju & $\begin{array}{l}\text { Std. } \\
\text { Error }\end{array}$ & Persamaan \\
\hline Kepala & 0,873 & 0,370 & 0,814 & 0,091 & $\mathrm{Y}=0,370 \mathrm{X}^{0,814}$ \\
\hline Tanduk & 0,897 & 0,000277 & 1,924 & 0,189 & $\mathrm{Y}=0,000277 \mathrm{X}^{1,924}$ \\
\hline Telinga & 0,960 & 0,022 & 1,229 & 0,072 & $\mathrm{Y}=0,022 \mathrm{X}^{1,229}$ \\
\hline Leher & 0,724 & 0,182 & 1,004 & 0,191 & $\mathrm{Y}=0,182 \mathrm{X}^{1,004}$ \\
\hline Tubuh & 0,892 & 0,547 & 0,923 & 0,093 & $\mathrm{Y}=0,547 \mathrm{X}^{0,923}$ \\
\hline Ekor & 0,963 & 0,297 & 0,928 & 0,052 & $\mathrm{Y}=0,297 \mathrm{X}^{0,928}$ \\
\hline
\end{tabular}

Tabel 2. Hasil analisis regresi power dimensi panjang tubuh kerbau lumpur betina

$\begin{array}{llllll}\text { Dimensi Panjang } & \text { R Konstanta } & \text { Laju } & \text { Std. } & \text { Persamaan }\end{array}$ Error

\begin{tabular}{lccccl}
\hline Kepala & 0,850 & 0,407 & 0,800 & 0,099 & $\mathrm{Y}=0,407 \mathrm{X}^{0,800}$ \\
\hline Tanduk & 0,948 & 0,00000014 & 3,267 & 0,220 & $\mathrm{Y}=0,00000014 \mathrm{X}^{3,267}$ \\
\hline Telinga & 0,726 & 0,328 & 0,750 & 0,142 & $\mathrm{Y}=0,328 \mathrm{X}^{0,750}$ \\
\hline Leher & 0,943 & 0,044 & 1,241 & 0,088 & $\mathrm{Y}=0,044 \mathrm{X}^{1,241}$ \\
\hline Tubuh & 0,935 & 1,464 & 0,750 & 0,057 & $\mathrm{Y}=1,464 \mathrm{X}^{0,750}$ \\
\hline Ekor & 0,921 & 0,193 & 1,018 & 0,086 & $\mathrm{Y}=0,193 \mathrm{X}^{1,018}$ \\
\hline
\end{tabular}

Berdasarkan hasil analisis regresi power (Tabel 1 dan 2) didapatkan hasil bahwa secara keseluruhan koefisien korelasi sangat nyata $(\mathrm{P}<0,05)$ pada masing-masing dimensi panjang kepala, tanduk, telinga, leher, tubuh dan ekor kerbau lumpur jantan.

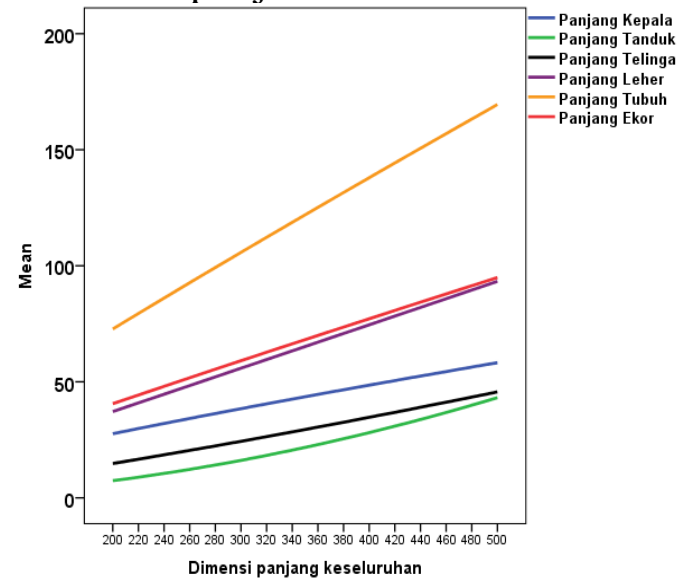

Gambar 2. Grafik laju pertumbuhan dimensi panjang tubuh kerbau lumpur jantan. betina pada Tabel 2. Laju pertumbuhan kerbau jantan dapat digambarkan dengan grafik yaitu pada Gambar 2 dan kerbau betina pada Gambar 3. Hasil perbandingan laju pertumbuhan dimensi panjang tubuh kerbau lumpur antara jantan dan betina pada Gambar 4 dan 5 
panjang kepala $(b<1)$ kemudian disusul oleh panjang tubuh $(b<1)$, panjang ekor $(b<1)$, panjang leher $(b=1)$, panjang telinga $(b=1)$, dan panjang tanduk yang tumbuh paling terakhir dengan laju $b>1$ serta bentuk grafik cekung.

Berdasarkan gambar 3. ukuran dimensi panjang tubuh yang paling besar yaitu panjang tubuh disusul oleh panjang ekor, leher, kepala, telinga dan panjang tanduk. Dari gambar grafik tersebut laju pertumbuhan yang lebih dini tumbuh yaitu panjang kepala $(b<1)$, panjang tubuh $(b<1)$ dan panjang telinga $(b<1)$ kemudian disusul oleh panjang ekor $(b=1)$, panjang leher $(b=1)$ dan panjang tanduk yang tumbuh paling terakhir dengan laju $b>1$ serta bentuk grafik cekung

Pada Gambar 4, laju pertumbuhan dimensi panjang kerbau lumpur jantan yang paling kecil panjang kepala yaitu sebesar 0,814 kemudian disusul oleh panjang tubuh, ekor, leher, telinga dan terakhir panjang tanduk sebesar 1,924. Pada Gambar 5, laju pertumbuhan dimensi panjang kerbau lumpur betina yang paling kecil panjang tubuh yaitu sebesar 0,750 kemudian disusul oleh panjang telinga, kepala, ekor, leher dan terakhir panjang tanduk sebesar 3,267.

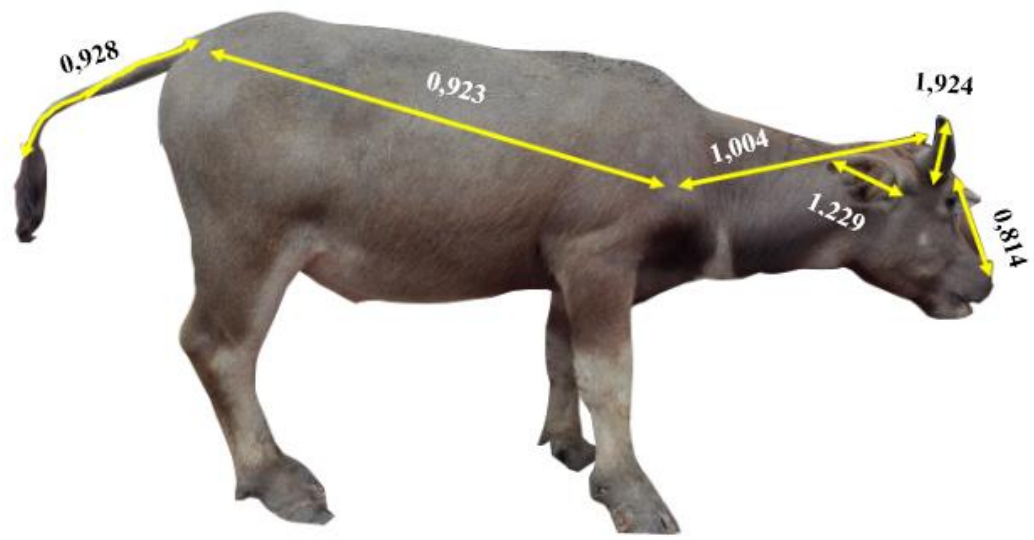

Gambar 4. Hasil nilai laju pertumbuhan dimensi panjang tubuh kerbau lumpur jantan.

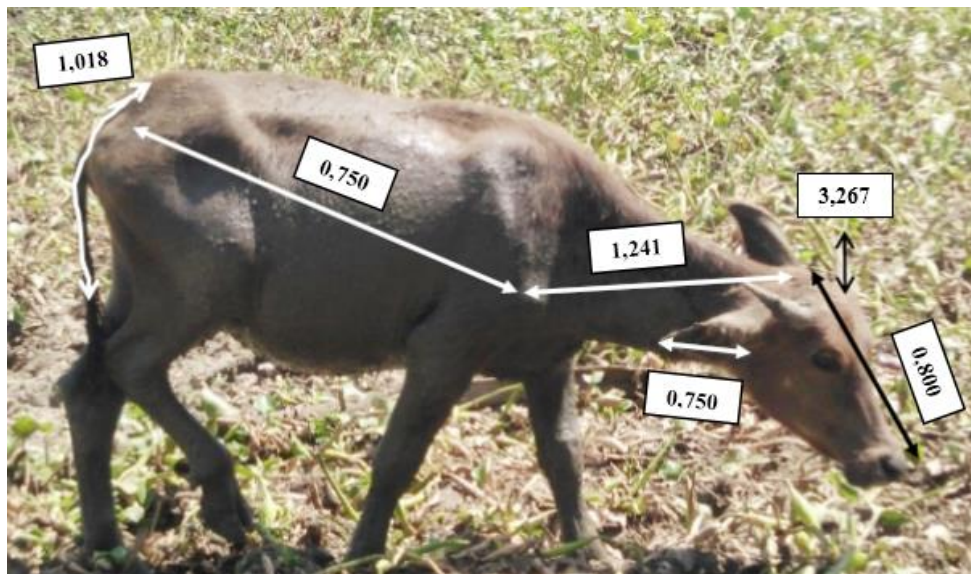

Gambar 5. Hasil nilai laju pertumbuhan dimensi panjang tubuh kerbau lumpur betina.

\section{Pembahasan}

Berdasarkan hasil penelitian didapatkan bahwa ukuran dimensi panjang tubuh kerbau lumpur (Bubalus bubalis) jantan berbeda nyata $(\mathrm{P}<0,05)$ dengan betina, serta terdapat interaksi antara jenis kelamin dan umur. Adanya interaksi antara jenis kelamin dan umur menunjukkan bahwa 
ukuran panjang tidak sejajar atau mempunyai laju pertumbuhan yang berbeda (Dharma et al., 2015).

Hasil perbandingan laju pertumbuhan dimensi panjang tubuh kerbau lumpur antara jantan dengan betina tertera pada Gambar 3 dan 4. Panjang kepala antara kerbau lumpur jantan dan betina tidak berbeda nyata. Hal ini disebabkan panjang kepala termasuk bagian tubuh yang terlihat tumbuh lebih dini. Bagian tubuh yang menggambarkan pertumbuhan tulang dan berfungsi lebih dulu, akan memiliki laju pertumbuhan yang hampir sama dengan yang lainnya (Dharma et al., 2015).

Panjang tanduk kerbau lumpur jantan sebesar 1,924 nyata lebih kecil dari betina sebesar 3,267. Dapat diartikan panjang tanduk kerbau lumpur jantan berkembang lebih dini daripada kerbau lumpur betina. Hal ini dikaitkan dengan fungsi tanduk bagi kerbau lumpur jantan. Menurut Darwin (1871) bahwa fungsi tanduk kerbau jantan sebagai senjata anti-predator atau proteksi diri dalam kompetisi pertarungan di habitatnya.

Panjang telinga kerbau lumpur jantan sebesar 1,229 nyata lebih besar dari betina sebesar 0,750. Laju pertumbuhan dimensi panjang telinga kerbau lumpur betina berkembang lebih dini dan potensi pertumbuhannya rendah. Sedangkan pada kerbau lumpur jantan berkembang lebih lambat dan potensi pertumbuhannya tinggi. Hal ini dikaitkan dengan fungsi fisiologis tubuh itu sendiri (Saptayanti et al., 2015). Telinga berfungsi sebagai alat pendengaran bagi kerbau lumpur. Pada penelitian ini kerbau lumpur lumpur betina memiliki fungsi fisiologis telinga lebih dini daripada kerbau lumpur jantan.

Panjang leher antara kerbau lumpur jantan dan betina tidak berbeda nyata. Hal ini sejalan dengan penelitian Dharma et al., (2015) yang mengatakan bahwa panjang leher sapi bali jantan dan betina tidak terdapat perbedaan yang nyata. Hal ini terjadi karena adanya adaptasi kerbau terhadap lingkungannya, dimana kerbau lumpur jantan dan betina di Kabupaten
Lombok Tengah menggunakan sistem penggembalaan di rawa-rawa dan berbagai tanaman hijau disekitarnya.

Panjang tubuh antara kerbau lumpur jantan dan betina berbeda nyata. Kerbau lumpur betina memiliki panjang tubuh yang berkembang lebih dini dan potensi pertumbuhannya rendah. Sedangkan pada kerbau lumpur jantan memiliki panjang tubuh yang berkembang belakangan dan potensi pertumbuhannya tinggi. Menurut Soeparno (2005) ternak jantan memiliki testosteron salah satunya steroid androgen, yaitu hormon pengatur pertumbuhan yang dihasilkan di sel-sel interstistial dan kelenjar adrenal. Testosteron dihasilkan pada testis jantan, sehingga pertumbuhan ternak jantan akan lebih cepat dibandingkan dengan betina, terutama setelah sifat-sifat kelamin sekunder muncul. Pada penelitian ini kerbau lumpur betina berkembang lebih dini, karena adanya peningkatan sekresi estrogen yang menyebabkan penurunan konsentrasi kalsium dan lipida dalam darah dan akan terjadi penurunan laju pertumbuhan tulang (Soeroso, 2004). Sehingga dapat dikatakan bahwa kerbau lumpur betina memiliki potensi pertumbuhan yang rendah (cepat berhenti tumbuh). Sementara pada jantan masih memiliki potensi pertumbuhan yang tinggi. Nantinya jika hormon androgen aktif pada ternak jantan, akan dapat merangsang dan menstimulasi pertumbuhan.

Panjang ekor kerbau lumpur jantan berbeda nyata sebesar 0,928 lebih kecil dari betina sebesar 1,018. Laju pertumbuhan dimensi panjang ekor kerbau lumpur jantan berkembang lebih dini dan potensi pertumbuhannya rendah. Sedangkan kerbau lumpur betina berkembang belakangan dan potensi pertumbuhannya tinggi. Hal ini dikaitkan dengan fungsi fisiologis tubuh itu sendiri (Saptayanti et al., 2015). Menurut Satayanarayana (2013) ekor merupakan organ penting bagi hewan yang berfungsi sebagai pertahanan tubuh, misalnya untuk menangkal lalat atau serangga, selain itu juga berfungsi sebagai penghilang stres tertentu pada kerbau. 
Hasil analisis regresi power (tabel 1 dan 2) sejalan dengan penelitian Sukri et al. (2016) yang menyatakan bahwa terdapat perbedaan parameter ukuran dimensi panjang kepala, leher, dan kaki kerbau lumpur Kabupaten Lombok Tengah $(\mathrm{P}<0,05)$ pada masing-masing kelompok umur. Hal ini terjadi karena selama pertumbuhan dan perkembangan serta peningkatan berat tubuh, terjadi perubahan komponen-komponen tubuh. Komponenkomponen tubuh secara kumulatif akan mengalami pertambahan berat mengikuti perkembangan badan selama proses pertumbuhan sampai mencapai dewasa tubuh (Soeparno, 2005).

Perbedaan laju pertumbuhan dimensi panjang tubuh kerbau lumpur jantan dan betina dapat dilihat dari Gambar grafik 1 dan 2. Perbedaan antar dimensi panjang tubuh dikaitkan dengan fungsi fisiologis tubuh itu sendiri (Saptayanti et al., 2015). Menurut Sampurna (2013) setiap organ, jaringan ataupun bagian tubuh pada setiap fase mempunyai kecepatan atau laju pertumbuhan yang berbeda. Perbedaan kecepatan ini disebabkan oleh perbedaan fungsi dan komponennya. Bagian tubuh yang berfungsi lebih dulu atau yang komponennya sebagian besar tulang akan tumbuh lebih dulu dibandingkan dengan yang berfungsi lebih belakang atau komponen penyusunnya terdiri dari otot maupun lemak. Secara kronologis menurut Palsson (1955) kecepatan pertumbuhan tubuh pada mulanya didominasi oleh perkembangan otak dan susunan saraf pusat. Disusul oleh tulang, otot, dan terakhir lemak.

Hasil penelitian antar dimensi panjang tubuh kerbau lumpur jantan dan betina menunjukkan dimensi panjang kepala lebih dini tumbuh kemudian disusul oleh panjang tubuh dan terakhir panjang leher. Hal ini tidak sejalan dengan penelitian Sampurna dan Suatha (2010) mengenai pertumbuhan alometri dimensi panjang tubuh pada sapi bali yang menyatakan panjang leher lebih dini tumbuh kemudian disusul oleh panjang kepala dan panjang tubuh. Menurut Tillman et al. (1991) dalam Sampurna dan Suatha (2010) menyatakan kecepatan pertumbuhan tulang kepala dan kaki, panjang badan dan otot, bagian dalam badan dan lemak, dipengaruhi oleh faktor pakan, sehingga tulang dan kaki berkembang lebih dini kemudian disusul oleh panjang badan dan otot, sedangkan lemak tumbuh paling lambat. Hal ini disebabkan pertumbuhan dan perkembangan tubuh dimulai dari bagian depan (kepala) bergerak ke bagian belakang tubuh dan bagian tubuh yang lain mulai dari ujung kaki menyebar keatas. Kedua pertumbuhan ini bertemu pada bagian tengah tubuh yang disebut dengan pertumbuhan "Antero-posterior dan centripetal” (Sampurna dan Suatha, 2010). Penelitian ini tidak sejalan dengan penelitian Sampurna dan Suatha (2010) disebabkan oleh adanya adaptasi kerbau terhadap lingkungan dan serta sistem manajemen pemeliharaannya. Pada kerbau lumpur di Kabupaten Lombok Tengah menggunakan sistem penggembalaan di rawa-rawa dan memanfaatkan berbagai tanaman hijau disekitarnya. Dalam hal ini panjang leher kerbau lumpur jantan dan betina di Kabupaten Lombok Tengah memiliki potensi pertumbuhan yang tinggi dan dapat membantu dalam mencari pakan hijauan. Pendapat tersebut sesuai dengan pernyataan Murtidjo (1989) yang menyatakan bahwa kerbau lumpur termasuk hewan yang memiliki leher panjang, sanggup hidup dengan makanan yang sederhana, cenderung hidup dan berkembang biak di daerah yang cukup air.

\section{SIMPULAN DAN SARAN}

\section{Simpulan}

Berdasarkan hasil penelitian dapat disimpulkan bahwa laju pertumbuhan dimensi panjang tubuh kerbau lumpur (Bubalus bubalis) jantan berbeda nyata dengan betina $(\mathrm{P}<0,05)$ di Kabupaten Lombok Tengah. Dimensi panjang tubuh kerbau lumpur jantan yang paling dini tumbuh yaitu dimensi panjang kepala kemudian disusul oleh panjang tubuh, 
panjang ekor, panjang leher, panjang telinga, dan yang terakhir tumbuh adalah panjang tanduk. Sedangkan dimensi panjang tubuh kerbau lumpur betina yang paling dini tumbuh yaitu dimensi panjang kepala, panjang tubuh dan panjang telinga, kemudian disusul oleh panjang ekor, panjang leher dan terakhir panjang tanduk yang memiliki laju pertumbuhan belakangan.

\section{Saran}

Perlu dilakukan penelitian lebih lanjut mengenai pola pertumbuhan dimensi panjang tubuh kerbau lumpur jantan dan betina yang bertujuan untuk mengetahui kapan dimensi panjang tubuh tercepat dan berhenti tumbuh.

\section{UCAPAN TERIMAKASIH}

Penulis mengucapkan terimakasih banyak kepada dosen pembimbing, penguji, Bapak Bur, Bapak Lubis, Bapak Sapowan selaku peternak kerbau lumpur di Kecamatan Praya Barat Daya, Kabupaten Lombok Tengah, yang telah membantu serta memberi dukungan atas terlaksananya penelitian ini.

\section{DAFTAR PUSTAKA}

Darwin C. 1871. The descent of man, and selection in relation to sex. $2^{\text {nd }} \mathrm{Ed}$. A. L. Burt, New York, Pp. 797.

Dharma IGNBS, Sampurna IP, Suatha IK. 2015. Pertumbuhan Dimensi Panjang Tubuh Pedet Sapi Bali. Indonesia Med. Vet. 4(5): 428-436.

Disnakkeswan Prov NTB. 2018. Populasi Ternak di Provinsi NTB Tahun 2016. [online]. Tersedia di: https://disnakkeswan.ntbprov.go.id/wp -content/uploads/2016/02/ PopulasiTernak-KabupatenKota-Tahun2016.pdf. Diakses tanggal 5 Agustus 2018.

Erdiansyah E, Anggraeni A. 2008. Keragaman Fenotipe dan Pendugaan Jarak Genetik antara Subpopulasi Kerbau Rawa Lokal di Kabupaten Dompu, Nusa Tenggara Barat,
Prosiding Seminar dan Lokakarya Nasional Usaha Ternak Kerbau, Tana Toraja: 24-26 Oktober.

Murtidjo BA. 1989. Memelihara Kerbau. Kanisius. Yogyakarta

Palsson H. 1955. Comformation and body. in pregess in of farm animal. $2^{\text {nd }} \mathrm{Ed}$. Edited by; J Hammond Butterworths. Sci. Publ.

Rachma ABS, Harada H, Ishida. T. 2011. The Estimation Of Growth Curve Of Bali Cattle At Bone And Barru Districts, South Sulawesi, Indonesia Using Ten Body Measurements. $J$. Indonesian Trop. Anim. Agric. 36(4) : 1-9.

Rachma ABS. 2007. Pertumbuhan dimensi tubuh pedet jantan sapi Bali di kabupaten Bone dan Barru Sulawesi Selatan. J. Sains Teknol. 7(2): 103-108.

Sampurna IP, Suatha IK. 2010. Pertumbuhan Alometri Dimensi Panjang dan Lingkar Tubuh Sapi Bali Jantan. J. Vet. 11(1): 6-51.

Sampurna IP. 2013. Pola pertumbuhan dan kedekatan hubungan dimensi tubuh sapi bali. Disertasi. Universitas Udayana. Denpasar.

Samsuandi R, Sari EM, Abdullah MAN. 2016. Performans reproduksi kerbau lumpur (bubalus bubalis) betina di Kecamatan Simeulue Barat Kabupaten Simeulu. J. Ilmiah Mahasiswa Pertanian. 1(1): 665-670.

Saptayanti NNJ, Suatha IK, Sampurna IP. 2015. Hubungan antara dimensi panjang induk dengan pedet pada sapi bali. Buletin Vet. Udayana. 7(2): 129136.

Satayanarayana G. 2013. Studies on affection of tail and its management in buffaloes. Sri Venkateswara Veterinary University. Thesis. Tirupati.

Soeparno. 2005. Ilmu dan teknologi daging cetakan keempat. Gadjah Mada University Press. Yogyakarta.

Soeroso. 2004. Performance kambing berdasarkan sifat kuantitatif dan kualitatif. Universitas Diponegoro. Semarang. 
Sugeng, Y. B. 2006. Sapi potong. Penebar Swadaya. Jakarta.

Sukri A, Fitriyani H, Supardi. 2016. Karakteristik morfologi kerbau lokal (Bubalus bubalis) Lombok Tengah Nusa Tenggara Barat. J. Biol. Pembelajarannya. 3(1) : 1-7.
Tillman ADH, Hartadi S, Reksohadiprojo S, Prawirokusumo S, Lebdosoekojo. 1991. Ilmu makanan ternak dasar. Jogjakarta. Fakultas Peternakan Universitas Gajah Mada. 